\title{
Inhibition of microvascular endothelial cell proliferation by vitreous following retinal scatter photocoagulation
}

\author{
Arvind Singh, Mike Boulton, Carol Lane, John Forrester, Joe Gaal, David McLeod
}

\begin{abstract}
Laser photocoagulation of pig retina induced breakdown of the blood-retinal barrier, with the appearance of serum proteins in the vitreous as determined by sodium dodecyl sulphate/polyacrylamide gel electrophoresis (SDS-PAGE) and immunoblotting techniques. Vitreous from lasered eyes inhibited the proliferation of cultured retinal microvascular endothelial cells in comparison with vitreous from non-lasered control eyes, and the inhibitory effect in the lasered eyes persisted for at least seven days. Inhibition was specific for endothelial cells, since no effect was observed when retinal pericytes or Tenon's fibroblasts were the target cells. These results suggest that indirect scatter photocoagulation may induce regression of neovascularisation by causing breakdown of the blood-retinal barrier and thus releasing into the vitreous serum components which result in inhibition of retinal microvascular endothelial cell growth.
\end{abstract}

Preretinal neovascularisation is responsible for many of the blinding sequelae of diabetic retinopathy. Neovascularisation occurs in response to ischaemic damage to inner retinal tissue and is thought to be mediated via diffusible angiogenic factor(s). ${ }^{1}$ Panretinal photocoagulation induces regression of the new vessels ${ }^{2}$ and has become an established primary therapy for preretinal neovascularisation.

The exact mechanism of regression of neovascularisation is unknown, but a number of hypotheses have been advanced to explain this effect. They include a proposed reduction in angiogenic factor release from ischaemic retina owing to destruction of retinal tissue, ${ }^{3}$ to increased availability of oxygen through thinned outer retina, ${ }^{4}$ or to disruption of the outer bloodretinal barrier facilitating outward diffusion of the angiogenic factor into the choroid. ${ }^{5}$ Recently, on the basis of tissue culture experiments, it has been suggested that the retinal pigment epithelium (RPE) may produce a factor capable of inhibiting the proliferation of vascular endothelial cells. ${ }^{6}$ However, RPE cells can also produce retinal vascular mitogens. ${ }^{7}$

In order to study the mechanisms underlying photocoagulation induced regression of neovascularisation we undertook scatter laser photocoagulation of pig retina and examined the properties of vitreous from lasered and unlasered eyes. ${ }^{8}$ Our initial study showed that vitreous from eyes which had received laser photocoagulation significantly inhibited the proliferation of retinal microvascular endothelial cells in vitro compared with vitreous from unlasered eyes. These results suggested that an inhibitor of angiogenesis is released from the retina after photocoagulation and diffuses into the vitreous, where it acts directly on preretinal new vessels. In the present study, we have extended this work to an analysis of vitreous proteins, and our results indicate that the major change in vitreous content following laser therapy is an influx of serum proteins and other components, the net effect of which is growth inhibitory activity specifically directed towards endothelial cells.

\section{Materials and methods}

\section{PHOTOCOAGULATION}

Eight 1-year-old miniature pigs received scatter photocoagulation by an argon blue-green laser (HGM Model 5, Litechnica) according to the following protocol. After premedication with 10 $\mathrm{mg} / \mathrm{kg}$ intramuscular ketamine $10 \mathrm{mg} / \mathrm{kg}$ methoxitone was administered intravenously to induce anaesthesia prior to intubation. Anaesthesia was maintained with spontaneous inhalation of a $30 \%$ $\mathrm{O}_{2} / 70 \% \mathrm{~N}_{2} \mathrm{O}$ mixture supplemented by $1.5 \%$ halothane. The animal's head was positioned on a slit-lamp and one thousand $500 \mu \mathrm{m}$ laser burns at $300 \mathrm{~mW}$ and $100 \mathrm{~ms}$ duration were applied to the retina of the right eye through a Goldmann fundus contact lens. The left eye was not lasered and served as the control for each animal. Following photocoagulation the anaesthetic agents were discontinued, and the animals recovered.

\section{PREPARATION OF VITREOUS}

Five of the animals were killed four days after photocoagulation and three after seven days. In each instance the animals were anaesthetised as described earlier and both eyes were enucleated. A blood sample was also taken from some of the animals, and the serum was separated and stored. The animals were killed by intravenous potassium chloride. The globes were immediately dissected and the vitreous was removed and stored at $-70^{\circ} \mathrm{C}$. Before use the vitreous was thawed, liquefied by an ultrasonicator (MSE Soniprep 150), and finally filter sterilised through a $0.22 \mu \mathrm{m}$ filter (Millipore, USA).

\section{CELL CULTURE}

Human eyes of variable age and with no known ophthalmic disease were obtained from Moorfields Hospital Eye Bank, London, after corneal 
buttons had been removed. Bovine eyes were collected from a local abattoir. Human RPE cells were isolated and cultured as previously described. ${ }^{9}$ Bovine retinal microvascular endothelial cells were grown in a 1:1 mixture of Dulbecco's modified Eagles medium (DMEM) with $7 \cdot 5 \%$ human platelet-poor plasma and pericyte conditioned medium. ${ }^{10}$ Bovine retinal pericytes and bovine Tenon's fibroblasts were routinely grown in DMEM supplemented with $20 \%$ fetal calf serum.

Cultures between the second and fifth passage were used for all subsequent studies.

\section{PRODUCTION OF CONDITIONED MEDIA}

Conditioned media were prepared as previously described. ${ }^{7}$ In brief, cultures of retinal pericytes and RPE cells were grown to confluence in 25 $\mathrm{cm}^{2}$ flasks (Falcon) and washed twice with Dulbecco's phosphate buffered saline without calcium and magnesium (PBSA). After they had been washed $8 \mathrm{ml}$ of DMEM supplemented with $7 \cdot 5 \%$ human platelet-poor plasma was added to each flask. After incubation for two days the conditioned medium was removed and stored at $-20^{\circ} \mathrm{C}$.

\section{PROLIFERATION ASSAYS}

$2 \times 10^{4}$ retinal microvascular endothelial cells were seeded into each gelatinised well of 24-well plates (Flow) in DMEM supplemented with $7 \cdot 5 \%$ human platelet-poor plasma. After a period of two days to allow for attachment and initial proliferation the medium was removed, and the cells were washed twice with plasma-free DMEM. Each well then received $1 \mathrm{ml}$ of one of the following test media:

(1) A 1:1 mixture of DMEM $+7 \cdot 5 \%$ plasma and pericyte conditioned medium to which was added $75 \mu \mathrm{l}$ liquefied vitreous (either 'lasered' or 'non-lasered') or $75 \mu \mathrm{l}$ PBSA as a control.

(2) A 1:1 mixture of DMEM $+7 \cdot 5 \%$ plasma and RPE conditioned medium to which was added $75 \mu \mathrm{l}$ liquefied vitreous (either 'lasered' or 'non-lasered') or $75 \mu \mathrm{l}$ PBSA as a control.

After two days in test media the cell numbers were determined by means of a haemocytometer. Each experiment was performed on at least two separate occasions.

Representative vitreous samples were also examined for their effect on pericyte and fibroblast proliferation. $2 \times 10^{4}$ cells were seeded in each well of uncoated 24 -well plates as described

Figure 1: Effect of 'lasered' and 'non-lasered' vitreous samples ( 4 and 7 days post treatment) on the proliferation of retinal microvascular endothelial cells in the presence of pericyte conditioned medium. The control consisted of a $1: 1$ mixture of $D M E M+7 \cdot 5 \%$ plasma and pericyte conditioned media to which was added $75 \mu l$ PBSA. In the test wells PBSA was substituted with $75 \mu$ l of vitreous (laser or non-laser). The vertical bars represent $S D$

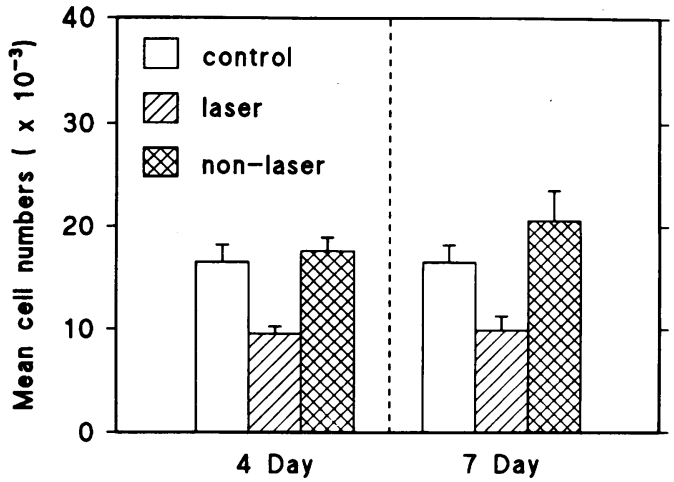

above and incubated overnight to allow for attachment and proliferation. The test media (DMEM $+7 \cdot 5 \%$ plasma mixed $1: 1$ with pericyte conditioned media) plus $75 \mathrm{ml} / \mathrm{l}$ of either vitreous or saline were added and cell numbers were determined at two days in the case of fibroblasts and at five days for pericytes, since the latter grew comparatively slowly.

Aliquots of cells from each test were stained with trypan blue in order to determine a cytoxic effect. Each experiment was performed on at least two separate occasions.

MIGRATION ASSAYS

Migration assays were undertaken as described by Hackett and Campochiaro using 48-well modified Boyden chambers." Briefly the lower wells were filled with test media consisting of 75 $\mathrm{ml} / \mathrm{l}$ of vitreous added to either DMEM with no serum or DMEM with $7 \cdot 5 \%$ fetal calf serum. Each test medium type was added to eight wells. Control wells had the vitreous substituted with an equivalent volume of PBSA. The wells were then overlaid with a type 1 collagen (Ethicon) coated polycarbonate membrane with $10 \mu \mathrm{m}$ pores and the chambers assembled. Upper wells were filled with a suspension of one of the cell types to be tested (endothelial cells, pericytes, $\mathrm{RPE}$, or fibroblasts) in serum free medium at a density of $9 \times 10^{5}$ cells $/ \mathrm{ml}$. The chambers were then incubated for six hours at $37^{\circ} \mathrm{C}$. The filter was removed, fixed in methyl alcohol, and stained with modified Wright's stain. The number of cells which had migrated through the polycarbonate filter were counted after the nonmigrating cells had been wiped from the top surface. Cell nuclei in 10 high power fields were counted in each well.

\section{GEL ELECTROPHORESIS}

Samples of vitreous $(1 \mu \mathrm{l})$ were analysed by SDS-PAGE in an $8-25 \%$ gradient gel by the Pharmacia Phast System according to the manufacturer's instructions. Samples were run under reducing and non-reducing conditions (with or without mercaptoethanol in the sample buffer).

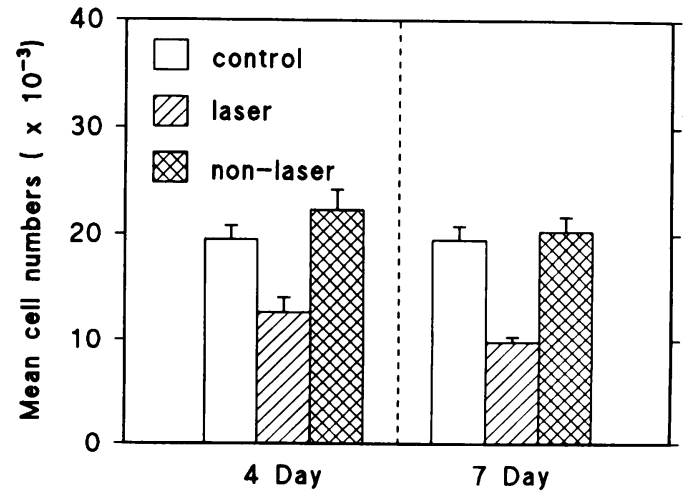

Figure 2: Effect of 'lasered' and 'non-lasered' vitreous samples (4 and 7 days post treatment) on the proliferation of retina microvascular endothelial cells in the presence of $R P E$ conditioned medium. The control consisted of a 1:1 mixture of $D M E M+7 \cdot 5 \%$ plasma and $R P E$ conditioned media to which was added $75 \mu$ l PBSA. In the test wells PBSA was substituted by $75 \mu$ l of vitreous (laser or non-laser). The vertical bars represent $S D$. 
In addition, native polyacrylamide gel electrophoresis of vitreous samples was performed. Gels were double stained with silver nitrate and Coomassie blue dye. Alternatively, proteins separated on the gels were transferred by diffusion blotting in the Pharmacia Phast System on to nitrocellulose membranes and detected with antisera against whole pig serum by the immunoperoxidase procedure according to the manufacturer's instructions. Samples of pig serum and haemolysed pig serum were run on the same gels for comparison.

\section{STATISTICS}

All data from the proliferation and migration assays were expressed as the mean together with standard deviation of the mean. The statistical significance of vitreous related changes was examined by analysis of variance.

\section{Results}

\section{PROLIFERATION ASSAYS}

Vitreous from all laser treated eyes significantly inhibited the proliferation of retinal microvascular endothelial cells in the presence of both pericyte and RPE conditioned media when compared with controls containing PBSA $(p<0.001)$ (Figs 1 and 2). In contrast, vitreous from unlasered eyes did not significantly affect endothelial cell proliferation $(p>0.8)$. There was no apparent difference in the degree of inhibition between laser exposed samples from four- and seven-day post-treatment animals in either the presence of pericyte conditioned medium or RPE conditioned medium.

The inhibition of proliferation by vitreous from laser treated eyes appeared to be specific for retinal microvascular endothelial cells, since

TABLE I The effect of vitreous from lasered and non-lasered eyes (four days after treatment) on the proliferation of pericytes and fibroblasts in DMEM $+7.5 \%$ plasma mixed $1: 1$ with pericyte conditioned medium. Mean values of six individual wells were made for each test medium. The numbers in parentheses are $S D$

\begin{tabular}{llll}
\hline & \multicolumn{4}{l}{ Mean number of cells $\left(\times 10^{-3}\right)$} \\
\cline { 2 - 4 } Cell type & Control & Lasered & Non-lasered \\
\hline Pericyte & $38(2 \cdot 2)$ & $39(2 \cdot 1)$ & $39(2 \cdot 5)$ \\
Fibroblast & $43(2 \cdot 6)$ & $43(1 \cdot 9)$ & $44(3 \cdot 0)$ \\
\hline
\end{tabular}

TABLE II Effect of vitreous from lasered and non-lasered eyes on the migration of retinal microvascular endothelial cells

\begin{tabular}{lll}
\hline & \multicolumn{2}{l}{ No. of cells migrated } \\
\cline { 2 - 3 } Test media & $\begin{array}{l}\text { Four days } \\
\text { post laser }\end{array}$ & $\begin{array}{l}\text { Seven days } \\
\text { post laser }\end{array}$ \\
\hline DMEM/O+ & $5 \cdot 2(1 \cdot 4)$ & $6 \cdot 6(2 \cdot 0)$ \\
PBSA & $5 \cdot 5(1 \cdot 9)$ & $6 \cdot 9(1 \cdot 5)$ \\
Lasered vitreous & $5 \cdot 0(1 \cdot 5)$ & $7 \cdot 1(1 \cdot 7)$ \\
Non-lasered vitreous & & \\
DMEM/7.5+ & $35 \cdot 7(4 \cdot 4)$ & $39 \cdot 0(4 \cdot 6)$ \\
PBSA & $37 \cdot 9(4 \cdot 6)$ & $41 \cdot 8(5 \cdot 7)$ \\
Lasered vitreous & $35 \cdot 7(6 \cdot 3)$ & $40 \cdot 6(5 \cdot 1)$ \\
Non-lasered vitreous &
\end{tabular}

DMEM/ 0 indicates serum-free DMEM and DMEM $/ 7 \cdot 5$ indicates DMEM supplemented with $7 \cdot 5 \%$ fetal calf serum. The figures represent the average number of migrated cell in 10 high power fields for each test medium and the numbers in parentheses are the inhibition was not seen with either' retinal pericytes or fibroblasts (Table I).

Trypan blue exclusion techniques did not demonstrate any cytoxic effect by any of the vitreous samples on the cells during the test period.

\section{MIGRATION ASSAYS}

The vitreous from either lasered or non-lasered eyes showed no apparent effect on the migration of either endothelial cells, pericytes, RPE, or fibroblasts in comparison with appropriate controls (Table II).

\section{GEL ELECTROPHORESIS}

In analysis by gel electrophoresis samples of vitreous from untreated eyes showed a small number of protein bands, as predicted for normal vitreous proteins (Fig 3). Samples from laser treated eyes showed a large increase in protein concentration, whose electrophoretic pattern was closely similar to that of pig serum (Fig 3). Immunoblotting of the proteins with

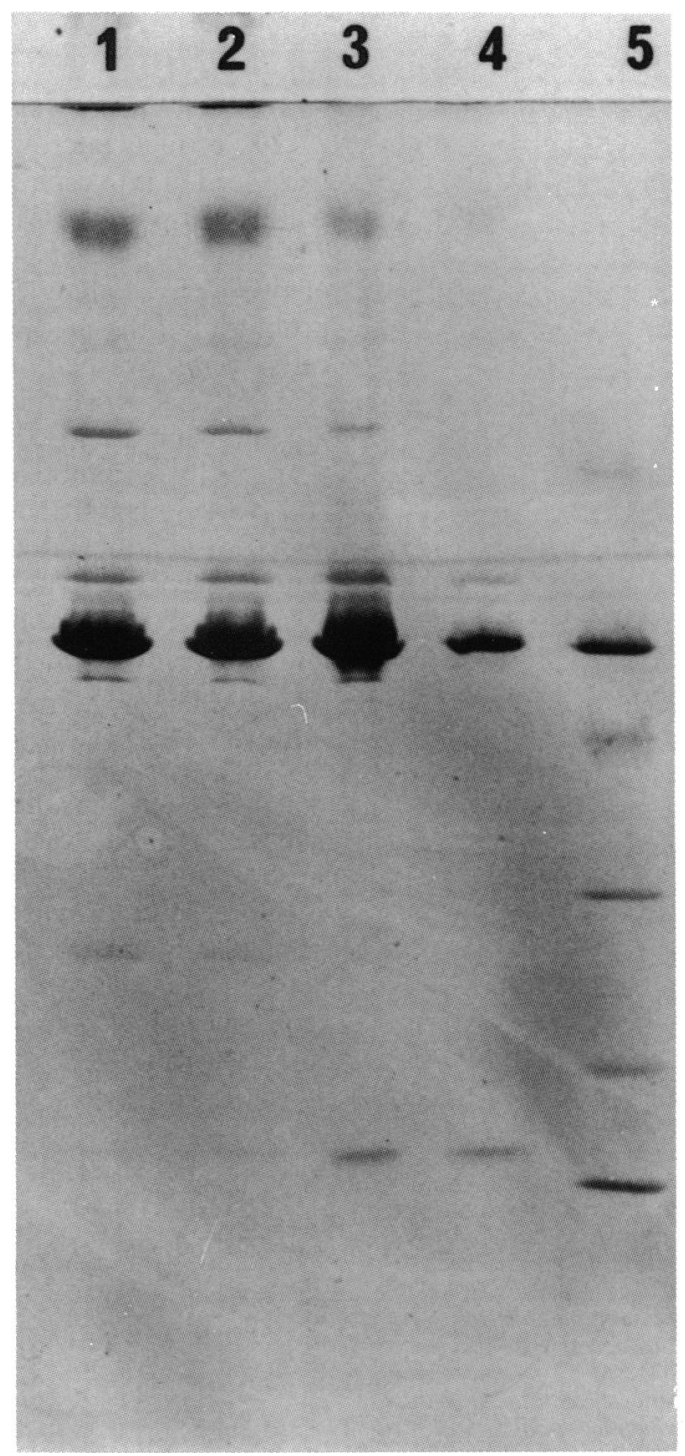

Figure 3: SDS-PAGE of vitreous samples from 7 day laser treated eyes. Track (I) pig serum; (2) haemolysed pig serum; (3) vitreous from laser treated pig; (4) vitreous from untreated pig; (5) molecular weight markers. 


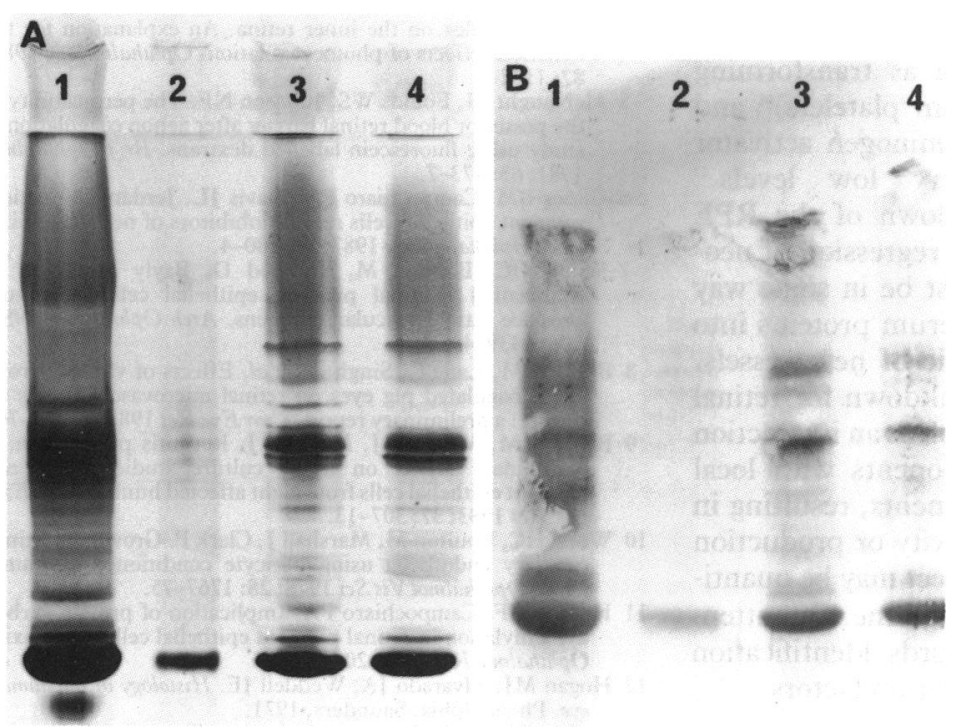

Figure 4: A: Native PAGE of vitreous samples from 7 day laser treated eyes. Track (1) vitreous from laser treated animal; (2) control vitreous from untreated animal; (3) pig serum; (4) haemolysed pig serum. B: Corresponding nitrocellulose immunoblot of samples, stained with rabbit anti-whole pig serum, with goat anti-rabbit as the second antibody.

antisera to whole pig serum confirmed that all additional proteins in laser treated vitreous samples were derived from serum (Fig 4). All laser treated samples from four- and seven-day post-treatment animals showed identical patterns with equivalent concentrations of individual proteins (Fig 5).

\section{Discussion}

We have confirmed our previous observation ${ }^{8}$ that following panretinal photocoagulation a diffusible factor(s) which inhibits microvascular cell proliferation appears to accumulate in the

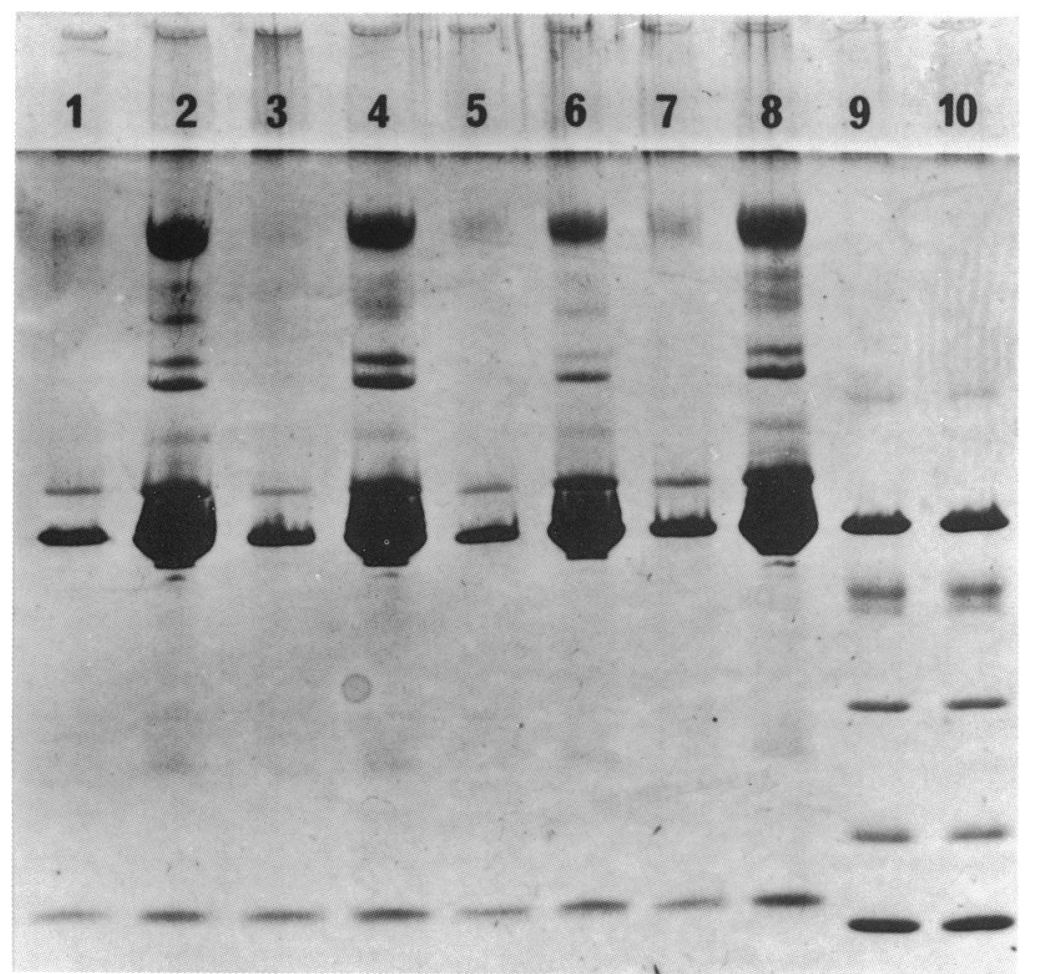

Figure 5: SDS-PAGE of vitreous samples from 4 day and 7 day laser treated eyes. Tracks 1, 3, 5, 7: control vitreous from untreated right eyes. Tracks 2, 4: vitreous samples from pig 1 and pig 2, 4 day laser treated eyes. Tracks 6, 8: vitreous samples from pig 3 and pig 4, 7 day laser treated eyes. Tracks 9, 10: molecular weight markers. vitreous. The inhibitory effect was present at both four and seven days after laser treatment. These time periods were chosen because clinical regression of neovascularisation is usually evident during this period following panretinal photocoagulation. ${ }^{2}$ Owing to the limited quantity of vitreous available it was only possible to (a) use one concentration of vitreous $(75 \mathrm{ml}$ vitreous/l of medium was chosen arbitrarily), and $(b)$ test the effect of 'lasered' vitreous on the response of microvascular endothelial cells to two mitogenic stimuli. We chose pericyte conditioned medium because pericytes are $(a)$ closely associated with retinal capillaries, ${ }^{12}$ (b) implicated in new vessel formation, ${ }^{13}$ and $(c)$ capable of producing culture medium which is mitogenic for retinal microvascular endothelial cells. $^{10}$ RPE conditioned medium was used because destruction of RPE cells after scatter photocoagulation results in regression of extraretinal neovascularisation, ${ }^{2}$ and RPE cells produce retinal vascular mitogens in vitro. ${ }^{7}$ Since no significant differences were observed in the degree of inhibition in the presence of either conditioned media, it is likely that the 'lasered' vitreous acted via the same mechanism in both media.

The inhibitory effect of vitreous from lasered eyes was specific for retinal capillary endothelial cells, since we observed no inhibitory effect on the proliferation of pericytes or fibroblasts in the presence of pericyte conditioned media. Since both pericytes and fibroblasts have previously been shown to respond to mitogenic factors in pericyte conditioned medium (Wong, unpublished) the results suggest that the mitogens which are responsible for endothelial cell proliferation are different from those for the other cell types studied.

Since the migration of retinal microvascular cells is as important as proliferation in new vessel formation, ${ }^{14}$ we examined the effect of lasered vitreous on the migration of retinal endothelial cells. Owing to the limited quantity of material available it was possible to examine the effect of vitreous only on serum induced migration. Thus, although vitreous had no effect on the migration of endothelial cells in the presence of serum, there may be an effect in the presence of conditioned media.

The nature of the laser induced inhibition of endothelial cell proliferation is obscure. Previously it has been suggested that RPE cells release an inhibitor of neovascularisation after laser injury, ${ }^{6}$ but RPE cells also release mitogens for endothelial cells, ${ }^{7}$ and clearly the role of RPE cells in this system is complex. Both xenon and laser photocoagulation cause damage to the outer blood-retinal barrier, ${ }^{515}$ and protein concentrations in the vitreous are known to be raised after laser treatment. ${ }^{15}$ While some of these proteins were acknowledged to have been derived from serum, it was also suggested by Campochiaro and colleagues that a contribution was derived from damaged retinal cells, in particular the RPE. ${ }^{15}$ In the present study we have shown that the great majority of the proteins in the vitreous after laser therapy are derived from serum and that serum proteins persist in the vitreous for at least seven days following laser treatment. 
Serum is known to contain inhibitors of endothelial cell proliferation such as transforming growth factor $\beta$ (derived from platelets) ${ }^{16}$ and other inhibitors such as plasminogen activator inhibitor-1, though at very low levels. ${ }^{17}$ However, for such a breakdown of the RPE blood-retinal barrier to cause regression of neovascularisation the effect must be in some way 'selective', since leakage of serum proteins into the vitreous is a characteristic of new vessels. The consequence of this breakdown for retinal endothelial cells probably involves an interaction of extravasated serum components with local retinal and/or vitreous components, resulting in either loss of stimulatory activity or production of inhibitory activity. This effect may be quantitative or cumulative over a long time. Our attention should be directed towards identification and characterisation of these serum factors.

This study was supported by the British Diabetic Association, London; Fight for Sight, London; Moorfields Eye Hospital Endowment Fund, London; Friends of Moorfields Eye Hospital, London; and the Help the Hospitals Charity, London. We are indebted to Stephen Rothery and Patrick Moriarty for their technical assistance.

1 Boulton M, McLeod D, Garner A. Vasoproliferative retinopathies: clinical, morphogenetic and modulatory aspects. pye 1988; 2 (suppl): S124-39.

2 Diabetic Retinopathy Study Group. Photocoagulation treatment of proliferative diabetic retinopathy: the second report
of diabetic retinopathy findings. Ophthalmology 1978; 85: of diabeti

3 Patz A. Clinical and experimental studies on retinal neovascularization. Am $\mathcal{F}$ Ophthalmol 1982; 94: 715-43.

4 Weiter JJ, Zuckerman R. The influence of the photoreceptor-
RPE complex on the inner retina. An explanation for the beneficial effects of photocoagulation. Ophthalmology 1980; 87: 1133-9.

5 McNaught EI, Foulds WS, Johnson NF. The permeability of the posterior blood retinal barrier after xenon coagulation: a study using fluorescein labelled dextrans. $\mathrm{Br} \mathcal{F}$ Ophthalmol $1981 ; 65: 473-7$.

6 Glaser BM, Campochiaro PA, Davis JL, Jerdan JA. Retina pigment epithelial cells release inhibitors of neovascularization. Ophthalmology 1987; 94: 780-4.

7 Wong HC, Boulton M, McLeod D, Bayly M, Clark P, Marshall J. Retinal pigment epithelial cells in culture produce retinal vascular mitogens. Arch Ophthalmol 1988; 106: 1439-43.

8 Boulton M, Lane C, Singh A, et al. Effects of vitreous from photocoagulated pig eyes on retinal microvascular cells in culture: a preliminary report. Curr Eye Res 1988; 7: 465-70.

9 Boulton M, Marshall J, Mellerio J. Retinitis pigmentosa: preliminary report on tissue culture studies of retinal pigment epithelial cells from eight affected human eyes. Exp Eye Res 1983; 37: 307-13.

10 Wong HC, Boulton M, Marshall J, Clark P. Growth of retinal capillary endothelia using pericyte conditioned medium. capilary endothelia using pericyte condition

11 Hackett SF, Campochiaro PA. Implication of protein carboxymethylation in retinal pigment epithelial cell chemotaxis. xymethylation in retinal pigme

12 Hogan MJ, Alvarado JA, Weddell JE. Histology of the human eye. Philadelphia: Saunders, 1971 .

13 Archer DB. Retinal neovascularisation. Trans Ophthalmol Soc UK 1983; 103: 2-27.

14 Glaser BM, Kalebic T, Garbisa S, et al. Degradation of basement membrane components by vascular endothelial cells: role in neovascularization. In: Ryan SS, Dawson AK, Little HL, eds. Retinal diseases. New York, Grune and Stratton, 1985: 21-4.

15 Campochiaro PA, Bryan JA, Conway BP, Jaccoma EH. Intravitreal chemotactic and mitogenic activity - implication of blood-retinal barrier breakdown. Arch Ophthalmol 1986; 104: 1685-7.

16 Masui T, Wakefield LM, Lechner JF, LaVeck MA, Sporn $M B$. Type $b$ transforming growth factor is the primary MB. Type $b$ transforming growth factor is the primary
differentiation-inducing serum factor for normal bronchial differentiation-inducing serum factor for normal bronchial
epithelial cells. Proc Natl Acad Sci USA 1986; 83: 2438-42.

17 Booth BA, Simpson AJ, Cooll A, Burnett B, McGregor IR. Booth BA, Simpson AJ, Cooll A, Burnett B, McGregor IR.
Plasminogen activator (PAI-1) in plasma and platelets. Br $\mathcal{f}$ Haematol 1988; 70: 327-33. 